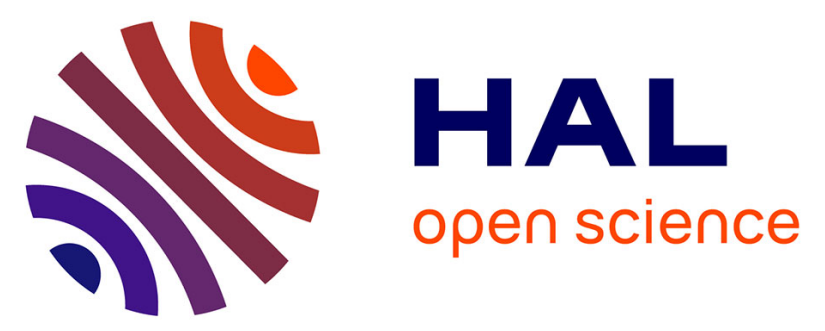

\title{
Deformation of $\mathrm{Mg}-\gamma \mathrm{Mg} 17 \mathrm{Al12}$ in situ composites: Room temperature mechanical behaviour, microstructures and mechanisms
}

Patricia Donnadieu, Souad Benrhaiem, Gilles Renou, Chunyang Zhang, Catherine Tassin, Jean-Jacques Blandin

\section{To cite this version:}

Patricia Donnadieu, Souad Benrhaiem, Gilles Renou, Chunyang Zhang, Catherine Tassin, et al.. Deformation of Mg- $\gamma \mathrm{Mg} 17 \mathrm{Al12}$ in situ composites: Room temperature mechanical behaviour, microstructures and mechanisms. Intermetallics, 2021, 132, pp.107127. 10.1016/j.intermet.2021.107127 . hal03143146

\author{
HAL Id: hal-03143146 \\ https://hal.science/hal-03143146
}

Submitted on 16 Feb 2021

HAL is a multi-disciplinary open access archive for the deposit and dissemination of scientific research documents, whether they are published or not. The documents may come from teaching and research institutions in France or abroad, or from public or private research centers.
L'archive ouverte pluridisciplinaire HAL, est destinée au dépôt et à la diffusion de documents scientifiques de niveau recherche, publiés ou non, émanant des établissements d'enseignement et de recherche français ou étrangers, des laboratoires publics ou privés. 


\title{
Deformation of $\mathrm{Mg}-\gamma \mathrm{Mg}_{17} \mathrm{Al}_{12}$ in situ composites: room temperature mechanical behaviour, microstructures and mechanisms
}

\author{
Patricia Donnadieu, Souad Benrhaiem, Gilles Renou, Chunyang Zhang, Catherine Tassin, Jean-Jacques Blandin \\ Université Grenoble Alpes, CNRS, SIMAP, F-38000 France
}

\begin{abstract}
Deformation tests at room temperature have been carried out on a series of in situ $\mathrm{Mg}-\gamma \mathrm{Mg}_{17} \mathrm{Al}_{12}$ composites with volume fraction of $\gamma \mathrm{Mg}_{17} \mathrm{Al}{ }_{12}$ phase varying between $20 \%$ and $60 \%$. Regardless of the phase volume fraction, these $\mathrm{Mg}-\gamma \mathrm{Mg}_{17} \mathrm{Al}_{12}$ composites that are prepared by solidification consist in magnesium-rich dendrites and a eutectic mixture. The eutectic mixture is made of magnesium fibres embedded in a matrix formed by the $\gamma \mathrm{Mg}_{17} \mathrm{Al}_{12}$ phase, a hard and brittle complex metallic alloy. Compression tests at room temperature have shown that a global plastic deformation is observed even though the soft phase is always enclosed in the brittle one. According to the strain-stress curve, deformation proceeds in two stages: a first stage at low stress $(\sigma \sim 100 \mathrm{MPa})$ and low strain $(\Delta \varepsilon<0.01)$ almost similar for all the composites and a second stage characterized by a strain hardening effect along with a significant deformation for composites with $\gamma$ phase volume fraction smaller than $40 \%$, whereas no or little additional deformation is observed for composites with volume fraction higher than $40 \%$ that break at high stress ( $400 \mathrm{MPa}$ ). Microstructural observations of the deformed samples have evidenced dislocations in the $\gamma \mathrm{Mg}_{17} \mathrm{Al}_{12}$ matrix and their localisation as pile-ups and slip bands as well as the transmission of deformation across the eutectic mixture. The plasticity of the $\gamma \mathrm{Mg}_{17} \mathrm{Al}_{12}$ phase and the mechanical behaviour of the $M g-\gamma \mathrm{Mg}_{17} \mathrm{Al}_{12}$ composites are discussed with respect to the microstructure characteristics and to the specific atomic features of complex metallic alloy phases.
\end{abstract}

keywords : intermetallics, complex metallic alloys, Mg-Al alloys, in situ composite, eutectic, room temperature deformation

\section{Introduction}

In the last decade, new composites containing complex metallic alloy (CMA) particles as reinforcement have been developed to improve the strength of light weight alloys. CMAs are intermetallic compounds having in common specific structural features, namely a local atomic tetrahedral packing leading to large and complex atomic clusters [1]. This includes quasicrystals, metallic glasses as well as the many intermetallic alloys earlier called Frank-Kasper phases [2] or Tetrahedrally Close Packed (TCP) phases [3]. While CMA phases are hard and usually brittle as bulk materials, composites containing CMA particles can exhibit high strength and large ductility. For instance, strength of $\sim 300 \mathrm{MPa}$ with ductility of $\sim 15 \%$ has been reported for Aluminium-based CMA composites containing large volume fraction of metallic glasses [4] or $\beta \mathrm{Al}_{3} \mathrm{Mg}_{2}$ particles [5] or quasicrystalline particles [6] [7]. These composites with a large amount of CMA particles (i.e. volume fraction up to 0.4 and even more) were prepared by powder metallurgy. But CMA composites can be also prepared by solid state phase transformation like precipitation [8], [9]. However as illustrated by Al-based composites containing quasicrystals, this process usually leads to a limited volume fraction of precipitates [6]. On the other hand, when the phase diagram of the system displays a eutectic mixture made of a simple and a complex metallic alloy, solidification in the vicinity of the eutectic point can be very efficient to prepare in situ composites with various volume fractions of complex phases.

Among many possible eutectic systems, the binary Mg-Al system [10] is of particular interest since its phase diagram displays a eutectic equilibrium involving the magnesium-rich solid solution $(\mathrm{Mg})$ and the $\gamma \mathrm{Mg}_{17} \mathrm{Al}_{12}$ phase that is one of the simplest CMA phases: namely a crystalline cubic structure with cell parameter $\mathrm{a}=1.04 \mathrm{~nm}$ and "only" 58 atoms per cell [11]. In a previous work, a series of $\mathrm{Mg} \gamma \mathrm{Mg}_{17} \mathrm{Al}_{12}$ composites containing a variable volume fraction of $(\mathrm{Mg})$ dendrites and a eutectic mixture composed of $(\mathrm{Mg})$ and $\gamma$ phase were prepared by solidification [12]. These Mg- $\gamma$ composites are characterized by a remarkable feature: the magnesium soft phase is embedded in the hard and brittle $\gamma$ phase. This microstructure strongly reminds that of the recently developed Bulk Metallic 
Glasses (BMG) in situ composites [13],[14]. The remarkable high strength and high ductility exhibited by the BMG composites are attributed to the presence of soft dendrites embedded in the BMG matrix. Therefore it seems relevant to study the mechanical behaviour of the $\mathrm{Mg}-\gamma$ composites paying a particular interest to the microstructure evolution with deformation.

The present work will report on the mechanical behaviour of the series of $\mathrm{Mg}-\gamma$ composites through compressive tests at room temperature, the related microstructures investigated by Scanning Electron Microscopy (SEM) and Transmission Electron Microscopy (TEM) and the interpretation of the results in terms of deformation mechanisms of the Mg- $\gamma$ composites with emphasis on the $\gamma$ phase structural specificities.

\section{Materials and methods}

Magnesium-based composites with various $\gamma \mathrm{Mg}_{17} \mathrm{Al}_{12}$ phase volume fractions $(60 \%, 50 \%, 40 \%, 30 \%, 20 \%)$ have been prepared by levitation melting from commercially pure ingots of magnesium and aluminium. For information, the (Mg)- $\gamma$ eutectic mixture corresponds to 64.5 vol.\% of the $\gamma$ phase. The experimental protocol to obtain composites with the desired volume fraction is described in details in [12]. The Mg- $\gamma$ composites will be labelled $\mathrm{Mg}-\mathrm{x} \% \gamma$ where $\mathrm{x} \%$ refers to the $\gamma$ phase volume percentage.

Table 1 displays for each targeted composite (line 1), the composition measured by inductively coupled plasma atomic emission spectroscopy (ICP-AES) (line 2), the volume fraction of the (Mg) dendrites measured by image analysis (line 3) and the corresponding eutectic mixture volume fraction (line 4). In line 5, the $\gamma$ phase volume fraction is calculated from the eutectic volume fraction assuming that the $\gamma$ phase ratio in the eutectic mixture is 0.645 as expected from the phase diagram computed with the Pandat software and the PanMg8 database [10]. For further use, Table 1 also gives the total (Mg) volume fraction, i.e. fibre + dendrite (line 6) and the volume fraction of the $(\mathrm{Mg})$ fibres in the eutectic mixture (line 7).

Table 1: Alloy composition and volume fraction of the various microstructural constituents of the Mg- $\gamma$ composites

\begin{tabular}{|l|l|l|l|l|l|}
\hline Composites & Mg-60\% $\gamma$ & Mg-50\% $\gamma$ & Mg-40\% $\gamma$ & Mg-30\% $\gamma$ & Mg-20\% $\gamma$ \\
\hline Composition (Mg wt. \%) & 68.1 & 71.0 & 74.5 & 78.9 & 83.7 \\
\hline (Mg) dendrites volume fraction & 0.07 & 0.21 & 0.40 & 0.56 & 0.72 \\
\hline Eutectic mixture volume fraction & 0.93 & 0.79 & 0.60 & 0.44 & 0.28 \\
\hline$\gamma$ phase volume fraction & 0.60 & 0.51 & 0.39 & 0.28 & 0.18 \\
\hline$(\mathrm{Mg})$ volume fraction (fibres + dendrites) & 0.40 & 0.49 & 0.61 & 0.72 & 0.82 \\
\hline$(\mathrm{Mg})$ fibres volume fraction & 0.33 & 0.28 & 0.21 & 0.16 & 0.10 \\
\hline
\end{tabular}

Compressive tests were carried out at room temperature using a MTS-4M machine operating at a strain rate of $2.5 \times 10^{-4} \mathrm{~s}^{-1}$. Samples for mechanical testing were machined by electro erosion as cylinders (diameter $3 \mathrm{~mm}$, length $5 \mathrm{~mm}$ ). As-cast and deformed samples were characterized by Scanning Electron Microscopy (SEM) on a LEO Stereoscan 440 and on a JEOL JSM-IT500HR LV. SEM images were acquired using the Back-Scattered Electron (BSE) detector. Samples for SEM were mechanically polished with diamond paste down to 0.25 micron or down to 3 microns with 1 micron water free OPS for final polishing. Specimens for TEM were mechanically polished with SiC paper down to a 50 micron thickness (final step at grade P2400) and ion milled with Argon ions accelerated at $4 \mathrm{keV}$ under $10^{\circ}$ incidence and at $3 \mathrm{keV}$ under $3^{\circ}$ in a GATAN PIPS 691 or at $3 \mathrm{keV}$ under $7^{\circ}$ and at 1 keV under $3^{\circ}$ in a GATAN PIPS 2.

A JEOL JEM 3010 Transmission Electron Microscope (TEM) operating at $300 \mathrm{kV}$ was used for Bright Field and Dark field imaging. A JEOL JEM $2100 \mathrm{~F}$ operating at $200 \mathrm{kV}$ equipped with the nanodiffraction tool ASTAR ${ }^{\text {tM }}$ [15] was used to retrieve orientation and phase maps by automated crystallographic data analysis. The method is based on 
the scanning of a narrow parallel beam on the TEM thin foil with acquisition of the diffraction pattern for each position. As explained in details in [16] and briefly recalled below, the crystallographic information is retrieved by indexation of the diffraction pattern data set by comparison to simulated diffraction patterns using a template matching technique. The simulation being done under kinematical condition, a precession by a small angle $\left(\sim 1^{\circ}\right)$ applied to the electron beam allows to reduce the dynamical effect and consequently to improve the indexation accuracy. The angular resolution is determined by the angular step size used to build the template data base as well as by the quality of the diffraction pattern. The resolution is currently better than $0.5^{\circ}$. The quality of the indexation is measured by a matching index and a reliability coefficient. The reliability is related to the ratio of the matching indexes for the two best solutions and by definition ranges from 0 to 100 (for a unique solution). Note that reliability values above 15 are considered as fully satisfactory [16]. Once indexation is achieved, misorientation profiles, orientation and phase maps can be produced.

Independently from the indexation, the diffraction data set can be used to form images called virtual Bright Field or virtual Dark Field images depending on the position of the virtual aperture. This virtual BF and DF images are analogous to the classical TEM BF and DF images, except that they are formed by a post treatment of the diffraction data set. Their spatial resolution is thus limited by the one of the diffraction data set (i.e. the step size or the probe size when the latter is larger than the step size). The point by point difference of neighbouring diffraction patterns can also be used to build correlation coefficient maps that are particularly efficient to highlight any sort of singularity giving rise to change in the diffraction patterns of neighbouring points: i.e. microstructural details like dislocations, phase and grain boundaries. These maps are also able to underline 3D features like tilted interfaces.

\section{Results}

It is worth mentioning that the microstructural features reported in the following have been observed in all the composites regardless of the $\gamma$ volume fraction. However, for full information, the $\gamma$ phase volume fraction corresponding to each image is indicated in the figure caption.

\subsection{Microstructure of the as cast $\mathrm{Mg}-\gamma$ composites}

The typical microstructure of the as cast Mg- $\gamma$ composites is illustrated by the SEM images in Fig. 1. In these BSE images, due to the $Z$ contrast, the magnesium-rich solid solution $(\mathrm{Mg})$ is evidenced by a contrast darker than the $\gamma \mathrm{Mg}_{17} \mathrm{Al}_{12}$ phase and the $\mathrm{Mg}-\gamma$ eutectic mixture. The $(\mathrm{Mg})$ dendrites are embedded in the eutectic mixture composed of (Mg) fibres surrounded by the $\gamma$ phase matrix (Fig. 1(a)). A halo of $\gamma$ phase continuously surrounds the $(\mathrm{Mg})$ dendrites except in a few locations as marked by dotted arrows in Fig. 1(a, b). However these local discontinuities do not allow for connecting neighbouring dendrites or dendrite arms. In Fig. 1(a, b, c) several eutectic cells can be observed. They are separated by eutectic cell boundaries characterized by coarse fibres as illustrated by Fig. 1(c).
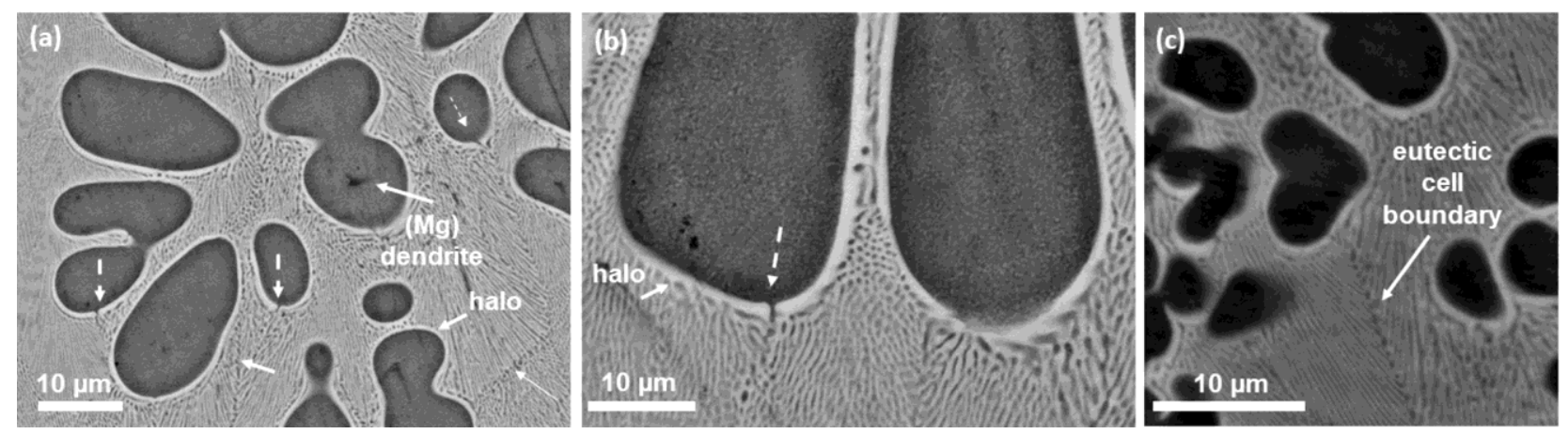
Fig. 1: Microstructure of the as cast Mg- $\gamma$ composites (SEM- back scattered electron contrast). (a) (Mg) dendrites embedded in the eutectic mixture. (b) Dendrites and eutectic cells imaged at higher magnification. Note the bright halo continuously enclosing the $(\mathrm{Mg})$ dendrites except for some rare discontinuities marked with dotted arrows in figures (a), (b). The morphological details within the various cell sections are consistent with a fibrous eutectic. (c) Eutectic cell boundary recognisable to the change in fibre orientation and to the presence of coarser fibres. (Mg- $40 \% \gamma$ composites)

Fine scale information on the eutectic microstructure has been obtained by TEM (Fig. 2). Unlike the previous SEM images, in the TEM images, the $\gamma$ phase is darker than the $(\mathrm{Mg})$ phase because of its higher diffraction contrast. Fig. 2(a, b) are consistent with the longitudinal and transverse views of a fibrous eutectic made of (Mg) fibres embedded in a $\gamma$ phase matrix. The $(\mathrm{Mg})$ fibres have a diameter between $\sim 0.1 \mu \mathrm{m}$ and $\sim 0.3 \mu \mathrm{m}$ depending on area (Fig.2(a, b)) and they frequently form a rather hexagonal pattern (Fig. 2(b)). The distance between fibres is corresponding to a $\gamma$ phase spacing of $\sim 0.2 \mu \mathrm{m}$ between the (Mg) fibres. However as illustrated by Fig. 2 (c) the fibrous microstructure is not always regular. In Fig. 2(c), several eutectic cells are evidenced by the diffraction contrast resulting from the difference of orientation of the $\gamma$ phase matrix. The eutectic cells are separated by boundaries pointed by black arrows in Fig. 2(c). As observed by SEM, a $\gamma$ phase halo of thickness $0.5 \mu \mathrm{m}$ is surrounding the dendrite. The $\gamma$ phase halo is continuous and the interface with the dendrite is locally flat except at the intersection with a eutectic cell boundary where the interface is making a cusp (Fig. 2(c)).

According to the colour coding of the orientation map of the as cast sample in Fig. 2(d), the fibre orientation varies over the area. A point to point misorientation profile taken across the $\gamma$ phase matrix (line marked by the double sided arrow in Fig. 2(d) shows that the misorientation is smaller than 0.5 degree. The relationships between the $\gamma$ phase matrix and various $(\mathrm{Mg})$ fibres have been retrieved and compared to the one reported by Gulberg and Ryum [17]. Experimental details are given in the supplementary material (Appendix A). No agreement was found with the Gulberg and Ryum relationship. Over the area shown in Fig. 2(d), the orientation varies and does not match with any simple orientation relationship. This crystallographic study being not useful in further comparison with deformed states, it is not reported here but provided as supplementary material. Generally speaking misorientations across the cell boundaries have no specific value. Owing to the orientation map, these misorientations can been measured. For the cell boundary in Fig. 2(e), the angle between eutectic cells is $5^{\circ}$. It corresponds to the smallest observed for the Mg- $\gamma$ eutectic system. It is worth noticing that in the area shown in Fig. 2(e), opposite to the one in Fig. 2(d), the fibre/matrix orientation relationship is constant within each eutectic cell. In our previous study [12], using conventional diffraction, we found that the orientation relationship was in agreement with the Gulberg and Ryum one. In the present study, the orientation maps obtained with ASTAR provide more complete information. In particular they reveal that the orientation relationships can vary over an area or be constant and when constant, it is not necessarily in agreement with the Gulberg and Ryum orientation relationships (see Appendix A of the supplementary material). 

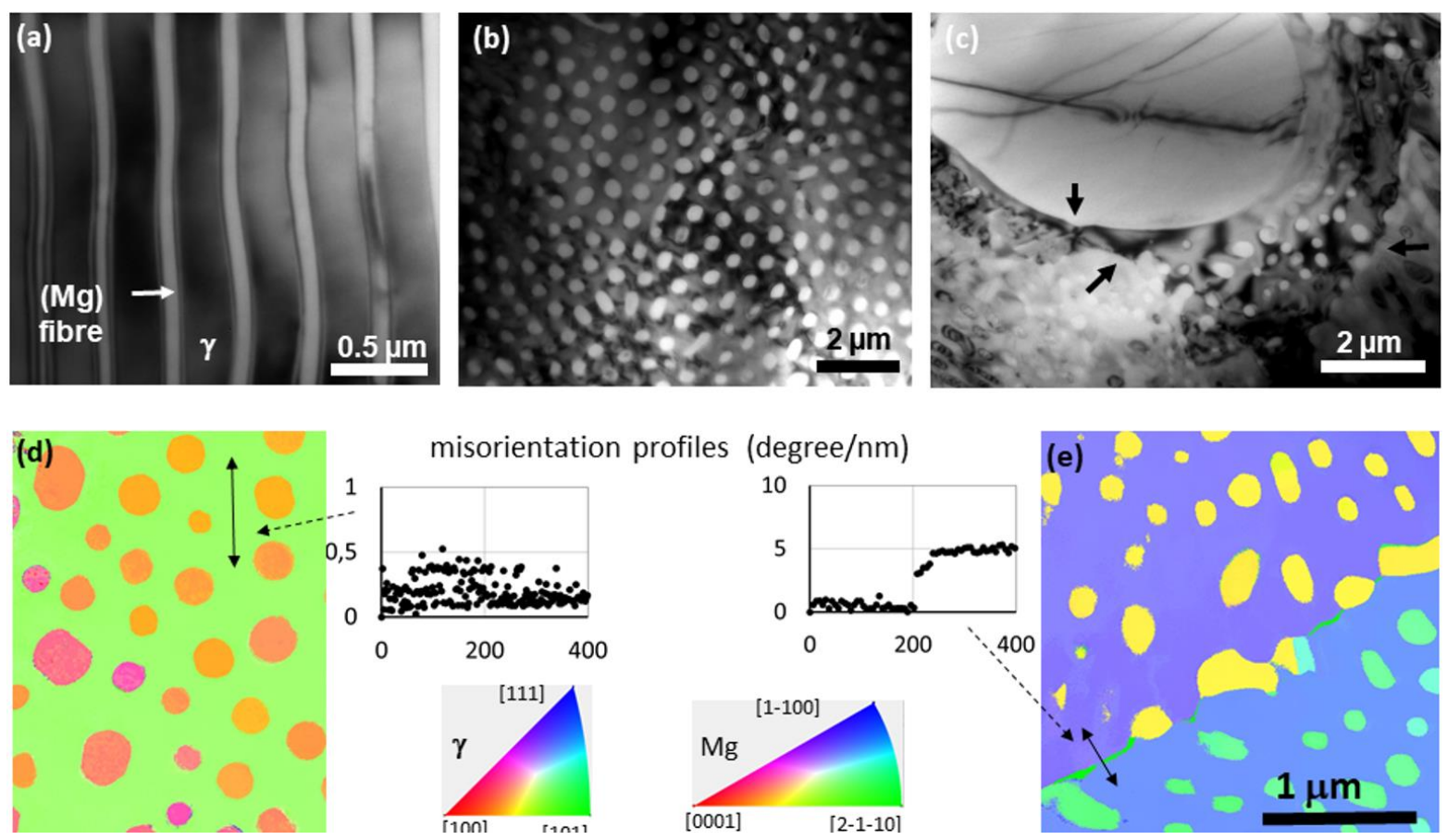

misorientation profiles (degree/nm)
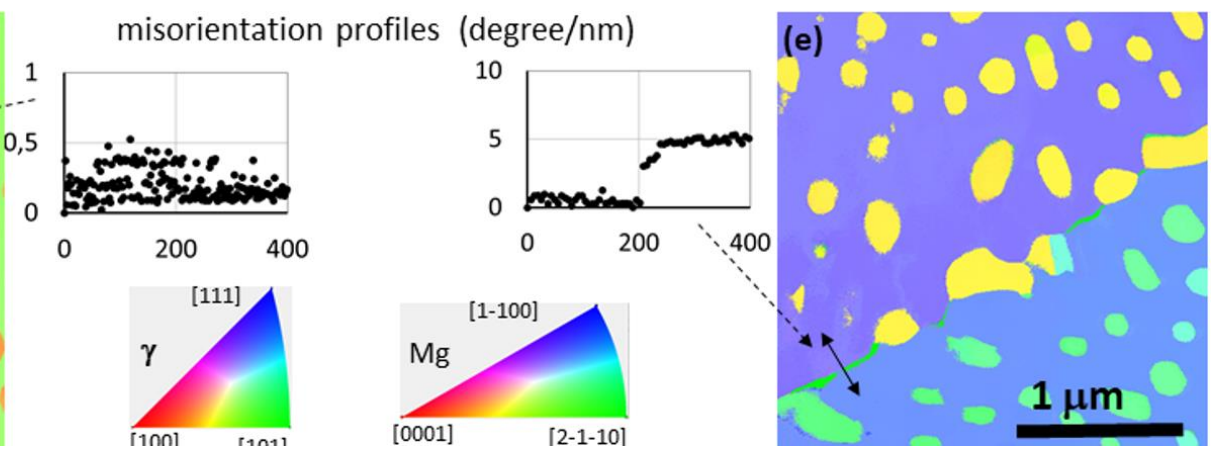

Fig. 2: Fine scale microstructure of the as-cast state. (a) and (b): TEM images recorded along different zone axes attesting for a fibrous morphology with $(\mathrm{Mg})$ fibres embedded in a $\gamma$ phase matrix and forming an almost hexagonal array. (a) (resp. (b)) zone axis normal (resp. parallel) to the fibre axis) (Mg-60\% rcomposite). (c) Interface between dendrite and eutectic mixture. The black arrows point eutectic cell boundaries recognizable to a change of the matrix diffraction contrast, coarser fibres and to a cusp at the interface (Mg-50\% r composite). (d) and (e): ASTAR orientation maps acquired with beam size 1.5 $\mathrm{nm}$, step size $2 \mathrm{~nm}$, precession angle $1.2^{\circ}$. (d): eutectic area showing a rmatrix with a unique orientation attested by the constant green colour over the area and by the profile over a distance of $400 \mathrm{~nm}$ (black arrowed line) showing point-to-point misorientation below $0.5^{\circ}$ (i.e. smaller than the angular resolution). The colour coding of the fibres indicates that the fibre orientation with respect to the matrix is changing over the area (Mg-30\% r composite). (e): eutectic area featuring a eutectic cell boundary. According to the profile across the boundary, this eutectic cell boundaries corresponds to a misorientation of $5^{\circ}$, the smallest we have observed for eutectic cell boundaries in the Mg- $\gamma$ system (Mg-50\% $\gamma$ composite).

\subsection{Deformation behaviour at room temperature}

The stress-strain curves obtained by compression tests at room temperature are reported in Fig. 3(a). The low strain deformation is consistent with an elastic deformation characterized by a bulk moduli ranging from $45 \mathrm{GPa}$ to $60 \mathrm{GPa}$ with increasing $\gamma$ phase volume fraction. For all the composites, the stress-strain curves exhibit a deformation stage characterized by an inflexion point at about $100 \mathrm{MPa}$ (Fig. 3(a)). As shown by the magnification in Fig. 3(b), for all the Mg- $\gamma$ composites, the inflexion point at $\sim 100 \mathrm{MPa}$ corresponds to a quite similar amount of plastic deformation $(\Delta \varepsilon \sim 0.01)$. 
(a)

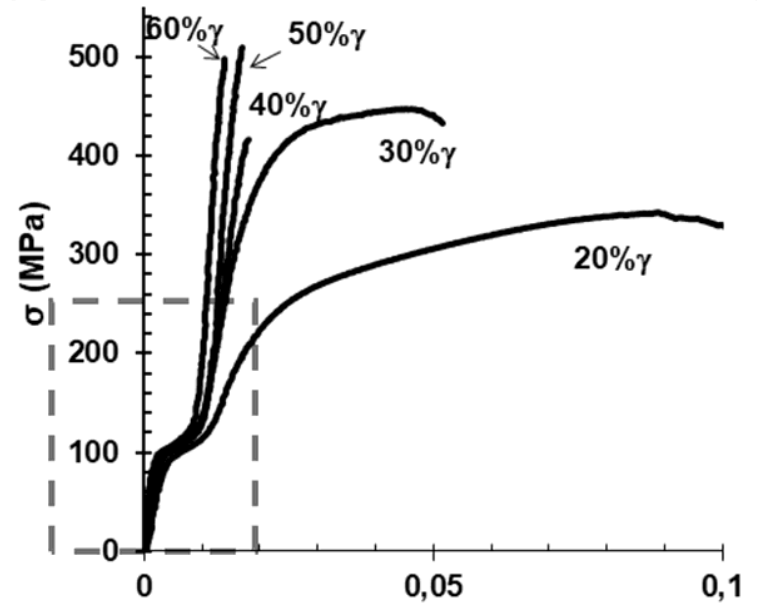

(b)

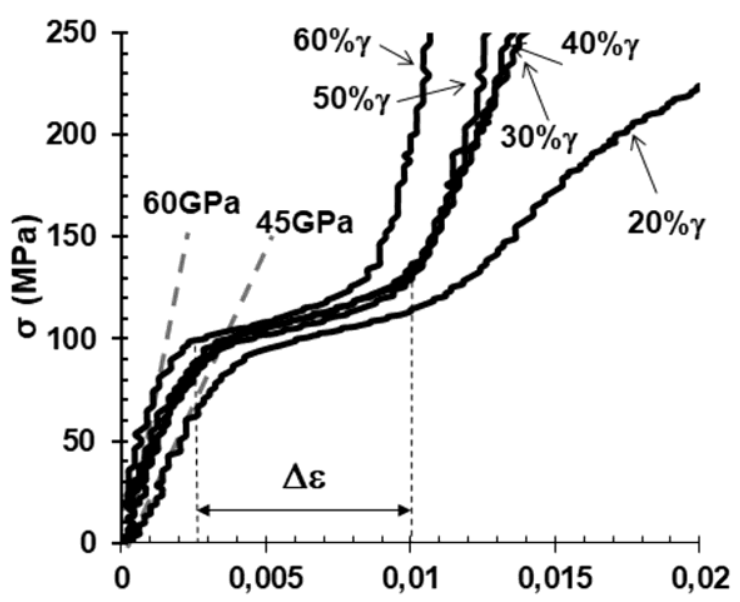

Fig. 3: Compressive stress-strain curves of the series of $\mathrm{Mg}$ - $\gamma$ composites at room temperature (a) and magnification on the low stress part (b). Note the inflexion point on the deformation curves present for all composites at about $100 \mathrm{MPa}$ and a deformation $\Delta \varepsilon \approx 0.01$.

After the low stress deformation stage, one observes a significant strain hardening effect, all the more pronounced with increasing amount of the $\gamma$ phase. Composites with $20 \%$ and $30 \% \gamma$ phase volume fraction exhibit a significant plastic deformation (up to $\varepsilon=0.1$ and 0.05 respectively) with a high maximum stress ( $\sigma=$ 350 and $450 \mathrm{MPa}$ respectively). On the other hand, the composites with a $\gamma$ phase volume fraction larger than $40 \%$ do not show a significant deformation - besides the low stress deformation stage - and break for $\varepsilon<0.02$ at a high stress ( $>400 \mathrm{MPa})$. It can be noted that this transition between a brittle and a ductile behaviour is observed at $40 \% \gamma$ phase, i.e. a dendrite volume ratio of $50 \%$ (Table 1 )

\subsection{Microstructure of deformed Mg- $\gamma$ composites}

The microstructures after deformation have been investigated in two states: specimens deformed in the low stress deformation stage and specimens deformed to fracture.

\subsubsection{The low stress deformation stage ( $\sigma \sim 100 \mathrm{MPa}, \Delta \varepsilon \sim 0.01$ )}

The microstructure of specimens after the low stress deformation stage is shown in Fig. 4. The (Mg) dendrites display traces consistent with thin twins in pyramidal planes (Fig. 4(a)) as well as dislocations lying in the basal and pyramidal planes (Fig. 4(b)). Regarding the eutectic mixture, only a few defect between fibres can be noticed like the one pointed by white dotted arrows in Fig. 4(c). However such defects are already present in the as cast material.
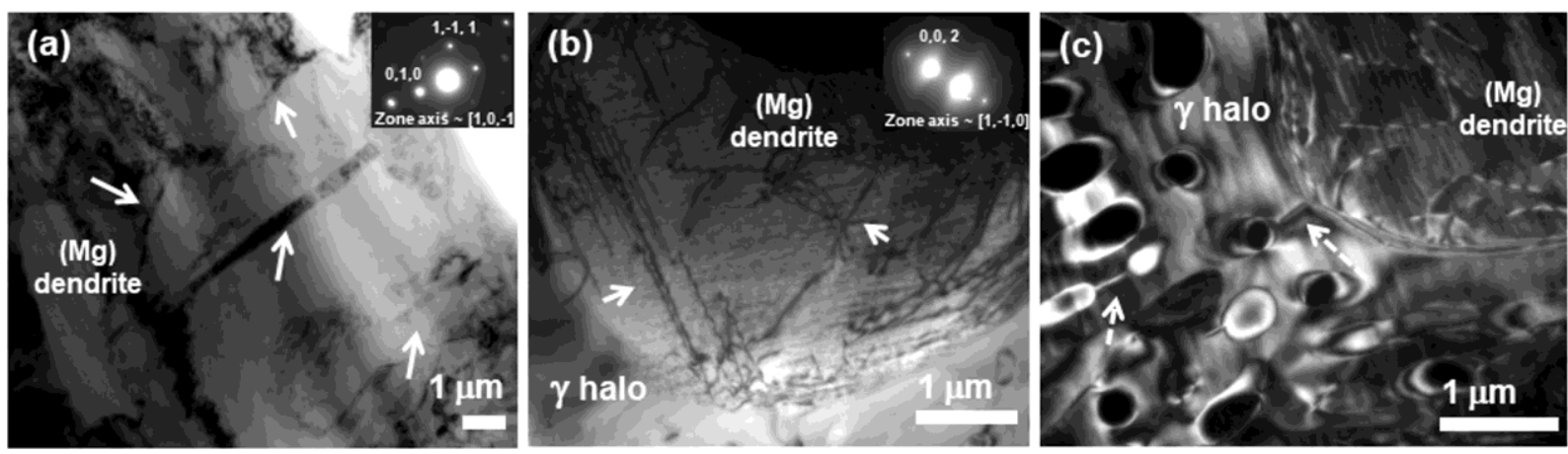

Fig. 4: TEM micrographs of specimens deformed up to the $100 \mathrm{MPa}$ inflexion point. (a) the white arrows point several twins in the (Mg) dendrite (Mg-40\% r composite) (b) Many dislocations lying along various planes can be observed in the (Mg) dendrite (Mg-60\% r composite). (c)TEM Dark Field image showing dislocations in the (Mg) dendrite and some rare defects (white dotted arrow) in the $\gamma$ phase matrix (Mg-40\% $\gamma$ composite) 


\subsubsection{Microstructures of $\mathrm{Mg}$ - $\gamma$ composites deformed to fracture}

Fig. 5 displays SEM images of specimens deformed to fracture. The area in Fig. 5(a) was located in the vicinity of the fractured surface while the one in Fig. 5(b) was at $1 \mathrm{~mm}$ from the fractured surface.

In the area close to the fracture, several cracks (indicated by white arrows in Fig. 5(a)) are seen across the eutectic mixture. Most of these cracks are normal to the dendrite/eutectic mixture interface and propagate along directions at about 45 degrees from the compression direction. The cracks are joining a dendrite (or dendrite arm) to a neighbour one through the eutectic mixture. No crack was observed in the (Mg) dendrite. For most of the cracks, the propagation seems to stop at the interface between the $\gamma$ phase and the $(\mathrm{Mg})$ dendrites.

Away from the fractured surface (Fig. 5(b)), no trace of cracks has been observed. The deformed sample displays the same microstructural features as earlier described in the as cast material, namely the fibrous eutectic microstructure, the $\gamma$ phase halo and the $(\mathrm{Mg})$ dendrites embedded in the eutectic mixture. As in the as cast state, the cell boundaries are characterized by coarser fibres than the eutectic cell (Fig.5(b)) and the $\gamma$ phase halo is continuous except in few locations corresponding to the intersection with eutectic cell boundary (dotted arrows in Fig.5(b)).

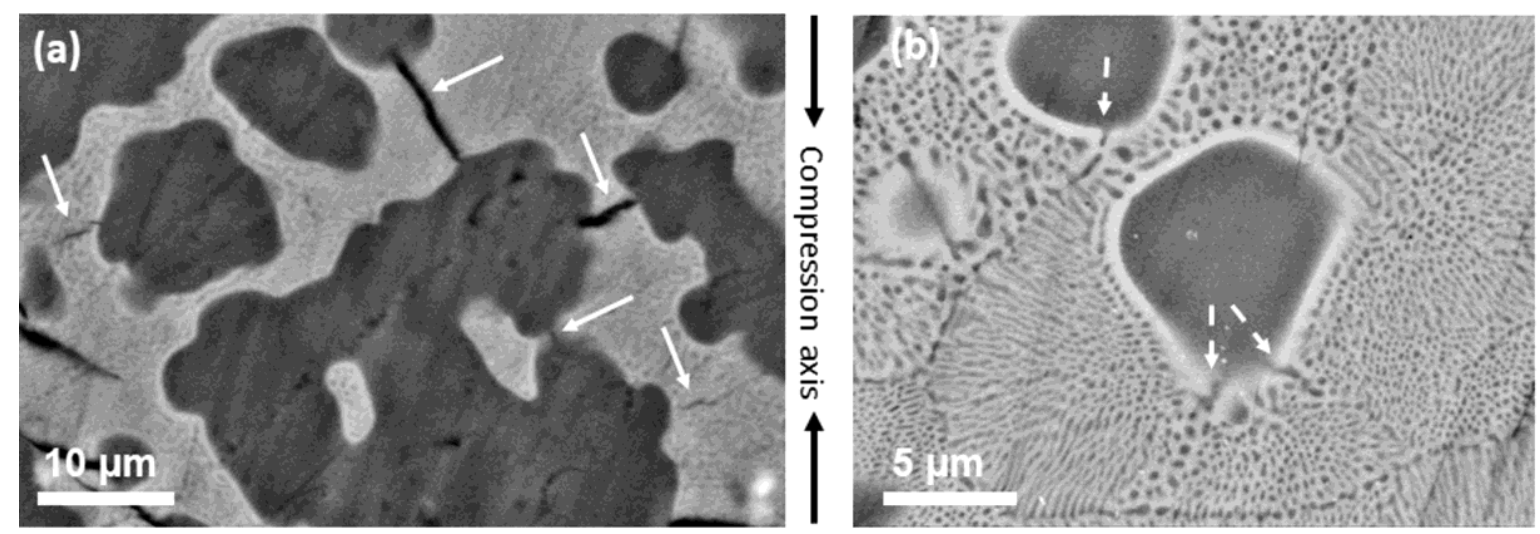

Fig. 5: Microstructure of a specimen deformed to fracture - compression direction parallel to the image width (SEM-back scattered electron contrast), (a) Area close to the fractured surface. More or less open cracks are crossing the eutectic mixture. They are close to the normal to the interface between $(\mathrm{Mg})$ dendrite and eutectic mixture. Most of them are at $45^{\circ}$ from the compression direction. Note that the black traces within the dendrites are due to polishing scratch. (b) Area at about $1 \mathrm{~mm}$ from the fractured surface no cracks are observed. As in the as cast state (Fig. 1), discontinuities of the halo surrounding the dendrite are observed. It is particularly obvious that they are associated to eutectic cell boundaries. (Mg$20 \%$ composite)

TEM images in Fig. 6 display microstructures observed in the magnesium dendrites of a specimen deformed to rupture. The dendrites show strong deformation contrast due mostly to dislocations (Fig. 6(a)). However less typical microstructures of possible relevance regarding the propagation of deformation have been noticed. For instance, Fig. $6(\mathrm{~b})$ shows a deformation contrast band crossing a dendrite as well as the $\gamma$ phase halo and continuing in the $(\mathrm{Mg})$ fibres of the eutectic cell boundary. 

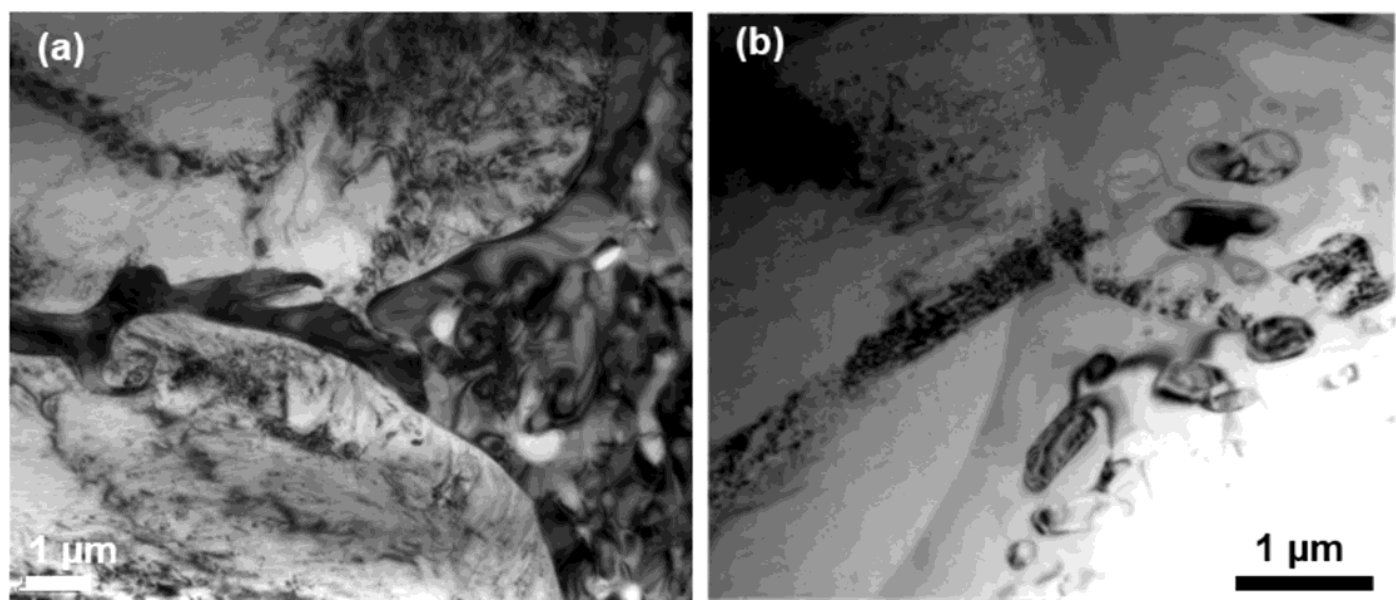

Fig. 6: Microstructure after deformation up to rupture (TEM Bright Field images) (a) Deformation contrast mostly due to dislocations is observed in the ( $\mathrm{Mg}$ ) dendrites. (b) Deformation contrast band traversing a (Mg) dendrite and extending inside a eutectic cell boundary (Mg-30\% r composite)

In addition, in samples deformed to rupture, traces of dislocations have been observed in the (Mg) fibres and in the $\gamma$ phase matrix of the eutectic mixture (Fig. 7). More precisely the DF TEM image in Fig. 7(a) is consistent with dislocations slipping in the plane perpendicular to the $(\mathrm{Mg})$ fibres and successively crossing the $\gamma$ phase matrix and the (Mg) fibres. The BF TEM image in Fig. 7(b) also shows a trace in agreement with the propagation of dislocation through the $\gamma$ phase matrix and a $(\mathrm{Mg})$ fibre. According to the diffraction pattern indexation, the slip plane associated to the dislocation in Fig. 7(b) is a (1-12) $\gamma$ phase plane. In both Fig. 7(a, b), the traces are consistent with dislocations propagating in a plane normal to the $(\mathrm{Mg})$ fibre axis and to the fibre/ $\gamma$ phase interface.
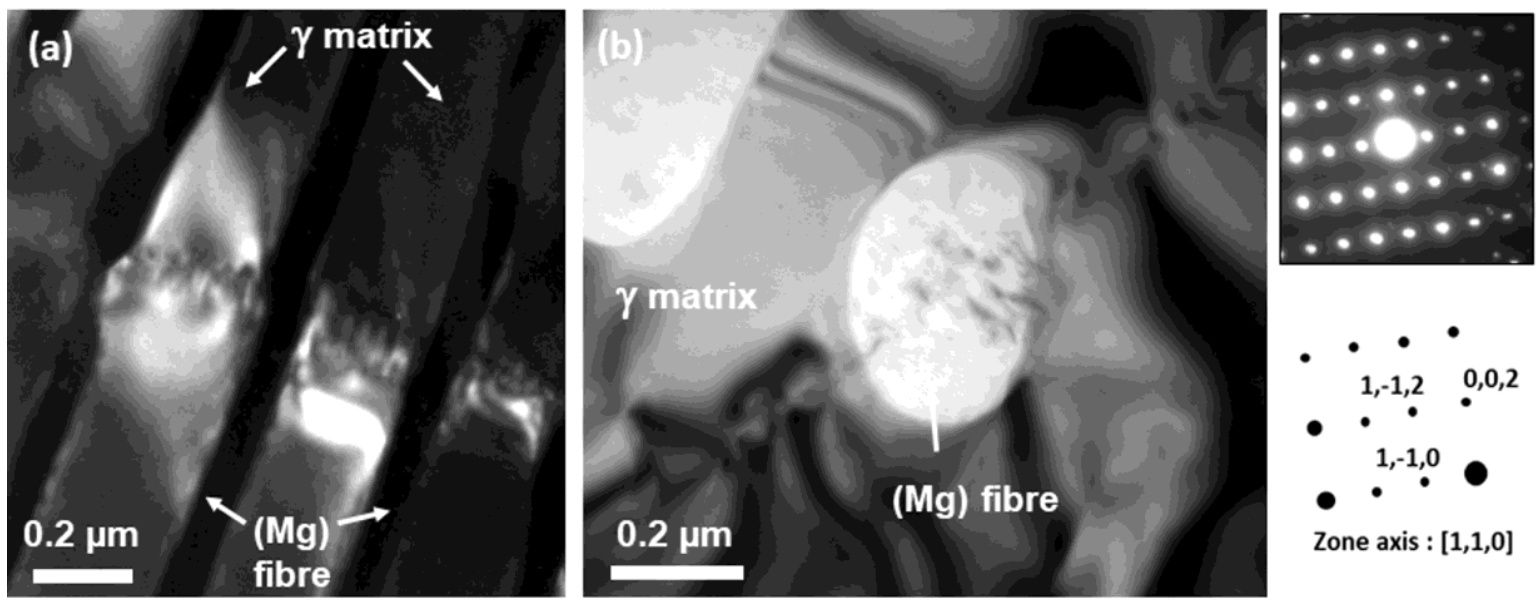

Fig. 7: Microstructures after deformation up to rupture. (a) Dark Field TEM image of a eutectic area showing fibres with their axis in the observation plane. Slip traces are observed running through the $(\mathrm{Mg})$ fibres and the $\gamma$ phase matrix along a direction normal to the $\mathrm{Mg} / \gamma$ interface. Note the striated contrast exhibited by the dislocation in the $\gamma$ phase. (Mg-60\% $\gamma$ composite) (b) Bright Field TEM image showing traces crossing the $\gamma$ phase and continuing in a (Mg) fibre. On the right side, the corresponding $\gamma$ phase matrix diffraction pattern indicates that the trace in Fig. $7(b)$ corresponds to a (1-12) plane. (Mg$40 \%$ composite)

In the course of the TEM investigation, it was noted that the contrast of the $\gamma$ phase defects was often differing from the usual contrast of dislocations: see for instance the striated contrast in the $\gamma$ phase (Fig. 7(a)) compared to the oscillating contrast of dislocations in a (Mg) dendrite (Fig. 4(c)). This effect can be explained by the complementary images presented in Fig. 8. For instance, in the pile-up observed in the spacing between fibres and the eutectic/dendrite interface (Fig. 8(a)), $\gamma$ phase dislocations are separated by about $100 \mathrm{~nm}$ and they show the usual dislocation oscillating contrast. On the other hand, within the eutectic mixture (Fig. 8(b)), traces of defects joining two fibres are showing the anomalous striated contrast earlier mentioned (Fig. 7(a)). Actually the 
corresponding diffraction pattern (Fig. 8(b)) shows spot splitting revealing a local misorientation of about $1^{\circ}$. Such misorientations are known for giving rise to a moiré contrast what can account for the striation on the defect traces. Consistently no misorientation was seen on the area showing the dislocation pile-up (Fig. 8(a)). Moreover, if we consider a pile-up of $\gamma$ phase edge dislocations with Burgers vectors $1 / 2<111>$ separated by $100 \mathrm{~nm}$, the resulting misorientation is smaller than $0.3^{\circ}$, therefore difficult to detect. Following the same line, the $\sim 1^{\circ}$ misorientation observed for the area in Fig. 8(b) would correspond to a pile-up of dislocations separated by distances smaller than $30 \mathrm{~nm}$. This short separation added to the moiré contrast can explain why dislocations do not show their usual contrast.
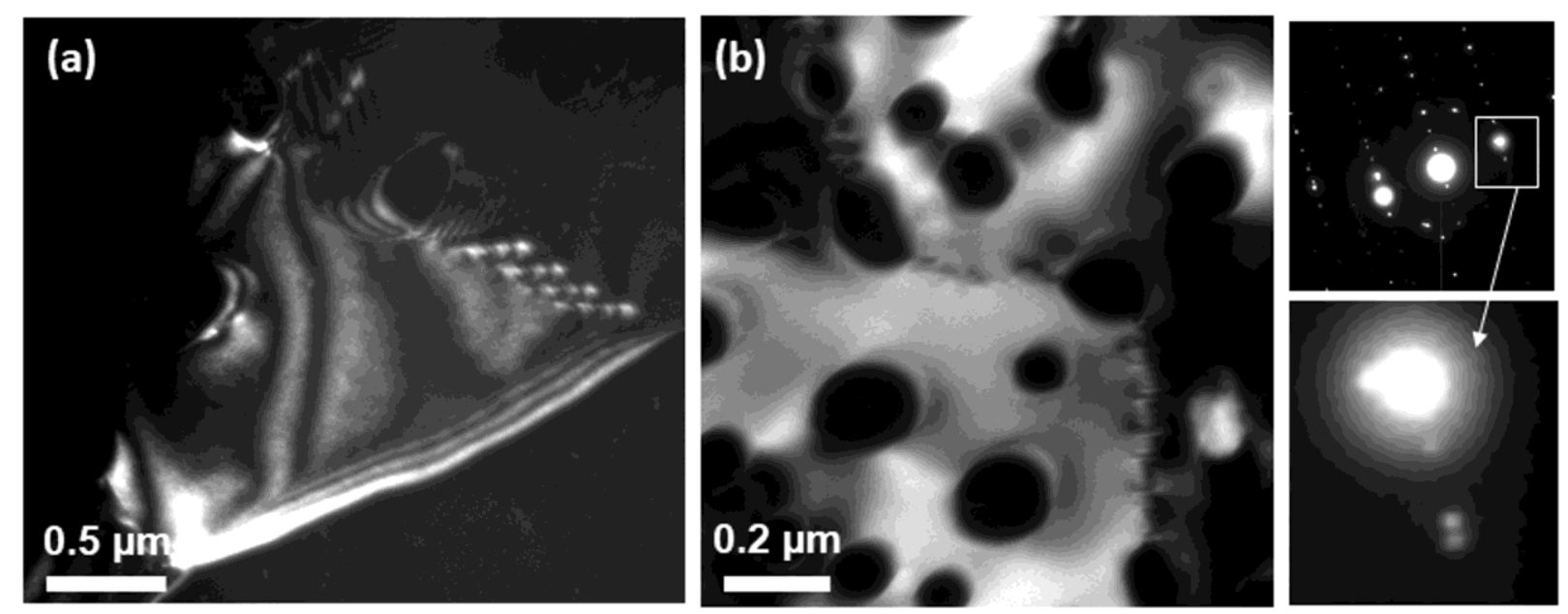

Fig. 8: Microstructure after deformation to rupture (TEM dark field images). (a) Dislocations in the $\gamma$ phase pile-up in the spacing between the dendrite interface and a close $(\mathrm{Mg})$ fibre. Note that the $\gamma$ phase dislocations are isolated and show the usual dislocation oscillating contrast. (Mg-30\% r composite) (b) Area showing defects between (Mg) fibres characterized by a striated contrast. A local misorientation is revealed by the spot splitting on the diffraction patterns (Mg-50\% $\gamma$ composite)

The diffraction contrast of the eutectic mixture in Fig. 9(a) suggesting that the eutectic cell is fragmented in small domains with different orientation, therefore an ASTAR study has been carried out on similar eutectic area reported in Fig. 9(b, c). The virtual dark field image (Fig. 9(b)) reveals several domains while the orientation maps attest by colour change for small misorientation (Fig. 9(c)). The profiles taken across several domain boundaries (Fig. 9(c)) measure misorientations between $2^{\circ}$ and $3.5^{\circ}$ (Fig. 9(d)). As for the defects with the striated contrast (Fig. 8(b)), these misorientations can be interpreted by a pile-up of dislocations. Assuming edge dislocation with $1 / 2<111>\gamma$ Burgers vector, the $2^{\circ}$ to $3.5^{\circ}$ would correspond to distance between dislocations of about 10 to 7 $\mathrm{nm}$. In other words, a strong localization of the deformation occurs and the formation of slip bands give rise to domains in the eutectic mixture cells.

It is worth noting that the boundaries observed in the deformed samples (Fig. 9(a), 9(b)) cannot be mistaken with the eutectic cell boundaries. Eutectic cells are several microns large while the domains observed in the deformed samples are smaller than 0.5 micron. Also the misorientations between domains in the deformed sample are significantly smaller than the $5^{\circ}$ value that is the smallest misorientation observed for eutectic cell boundaries (Fig. 2(e)). 

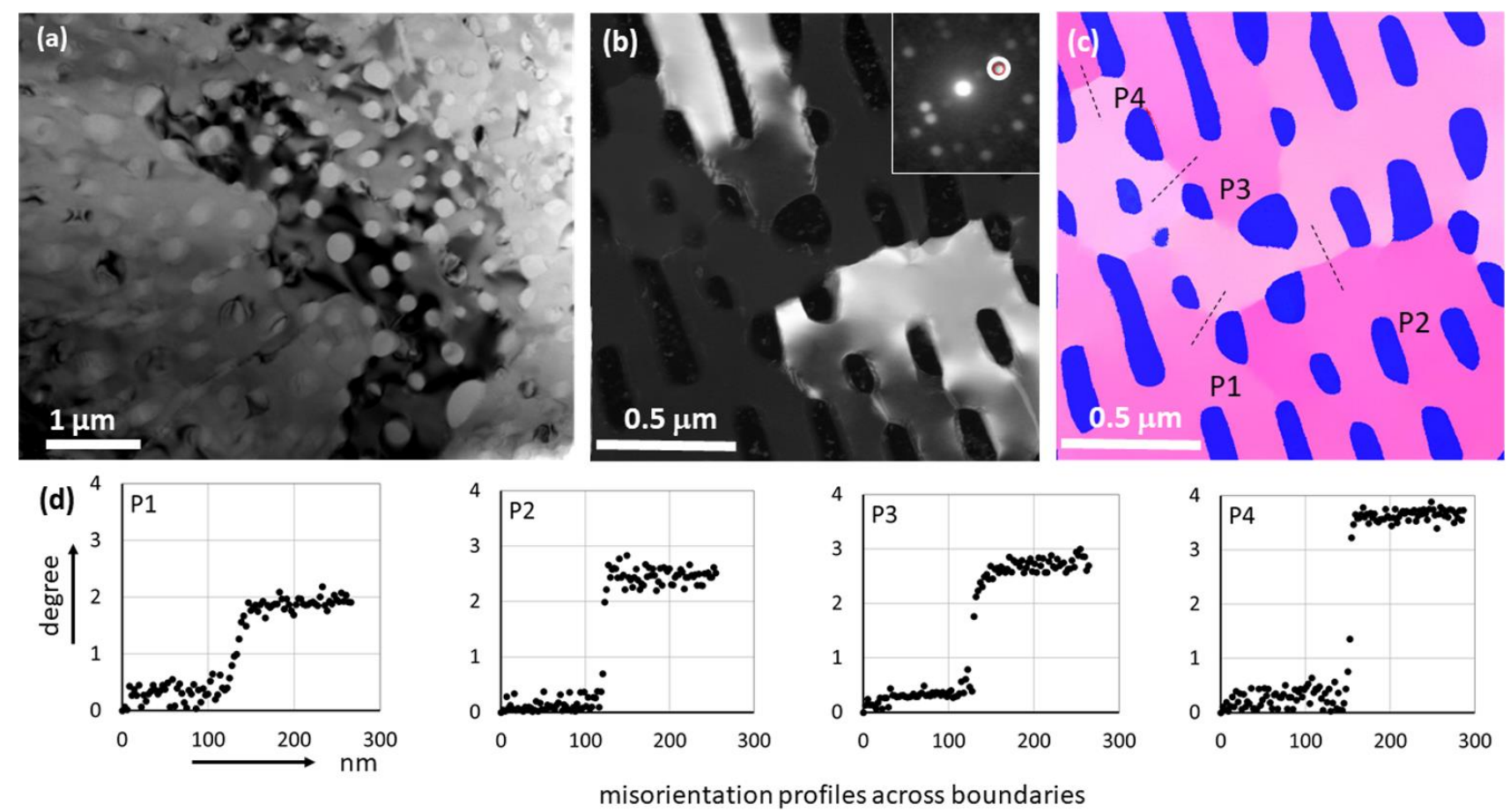

Fig. 9: Microstructure after deformation to rupture. (a) TEM bright field images showing micro-sized domains inside the eutectic cell. (b) Virtual Dark Field image revealing domains with different diffraction contrasts separated by boundaries showing dislocation like features. (c) Orientation map of an area located in the eutectic mixture. The colour coding points out small orientation changes in the $\gamma$ phase matrix while the fibres exhibit a unique orientation confirming the presence of only one eutectic cell in this area (d) Misorientation profiles across the boundaries labelled P1 to P4. (Mg-50\% r composite)

Regarding the vicinity of dendrites, Fig. $10(a, b, c)$ displays the TEM BF image, the orientation map and the correlation map of an area showing the eutectic mixture and part of a dendrite. Like in the as cast state (Fig. 2 (d)), the colour coding of the orientation map (Fig. 10(b)) points that the (Mg) fibre orientation with respect to the $\gamma$ phase matrix slightly varies across the eutectic mixture. In this area the orientation relations are found in partial agreement with the Gulberg and Ryum one (details in Appendix A of the supplementary material). The halo at the dendrite /eutectic mixture interface is indexed as a $\gamma$ phase with a high reliability. However, opposite to what is observed in the as cast state, the dendrite/eutectic mixture interface is not flat but displays a series of cusps as marked by arrows on the orientation map (Fig. 10 (b)). The correlation map (Fig. 10(c)) reveals that the (Mg) fibres are characterized by a high density of defects while the $\gamma$ phase matrix appears quite featureless except for localized singularities in the vicinity of the cusps mentioned above, i.e. in the $\gamma$ phase halo narrow spacing of about 0.5 micron between the dendrite interface and the closest fibre. A series of orientation profiles P1 to P5 has been measured (Fig. 10(C)). For reference a profile (P) has been taken in a featureless area: it is characterized by very small misorientations, less than $0.5^{\circ}$ over a $200 \mathrm{~nm}$ range as was observed in the as cast state (Fig. 2(d)). On the contrary, the profiles $\mathrm{P} 1$ to $\mathrm{P} 5$ all display an abrupt change of about $1^{\circ}$ to $1.5^{\circ}$. The virtual dark field images shown in Fig. 10(d) suggest that dislocations are present in these narrow spacing. If we assume a pile-up of $1 / 2<111>\gamma$ phase edge dislocations, the $\sim 1^{\circ}-1.5^{\circ}$ misorientation corresponds to a dislocation spacing of $50 \mathrm{~nm}$ and a piling of about fifteen dislocations in this narrow area. Actually the virtual DF image features, the localized singularities revealed by the correlation maps and the measured misorientation are consistent with deformation localized in the narrow spacing at the interface with the $(\mathrm{Mg})$ dendrite. We note that this localisation is associated to an accumulation of dislocations in the $(\mathrm{Mg})$ dendrite in the vicinity of a cusp that is marked by a white dotted arrow on the virtual DF field image (Fig. 10(e)). 

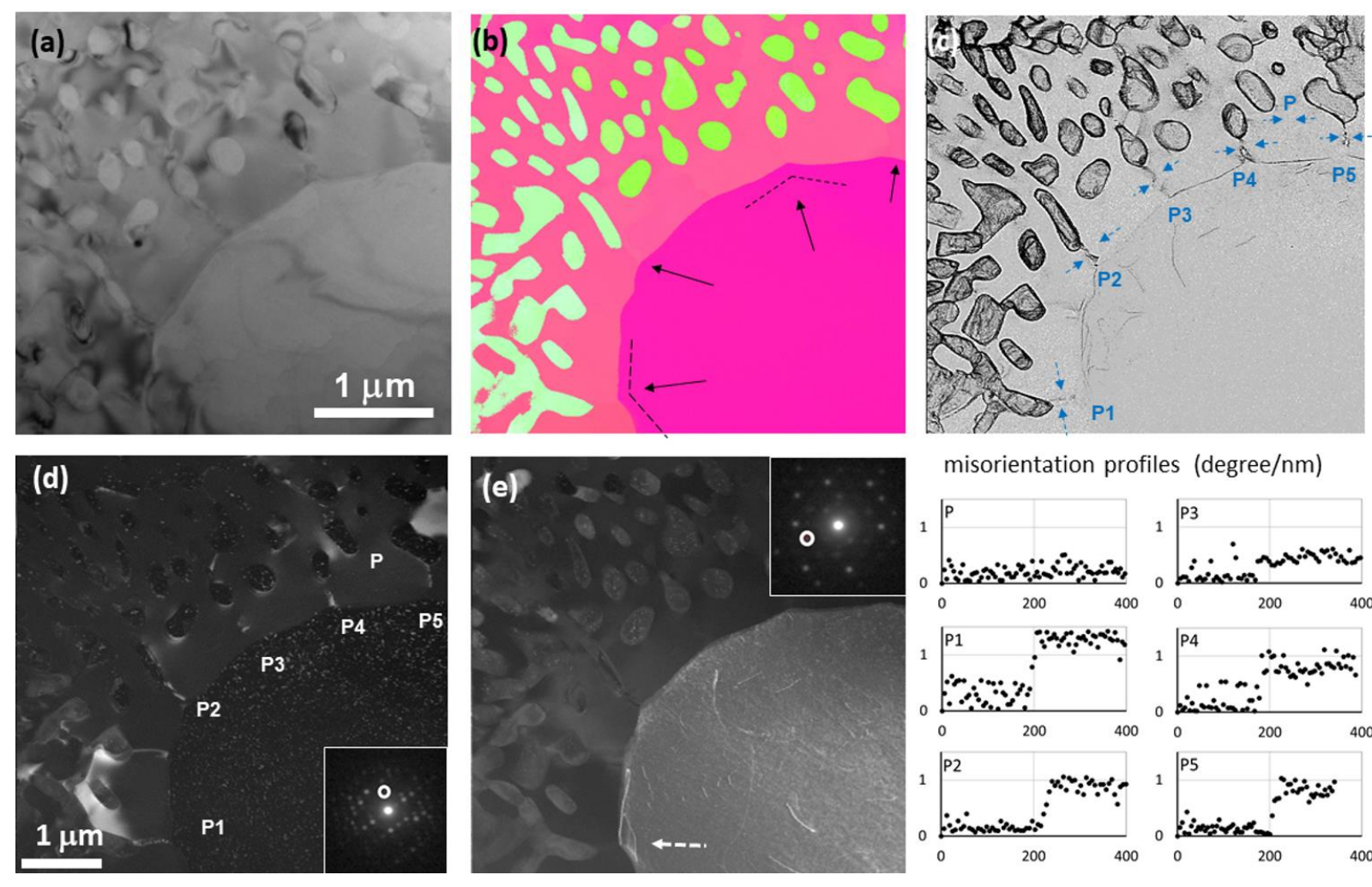

misorientation profiles (degree/nm)

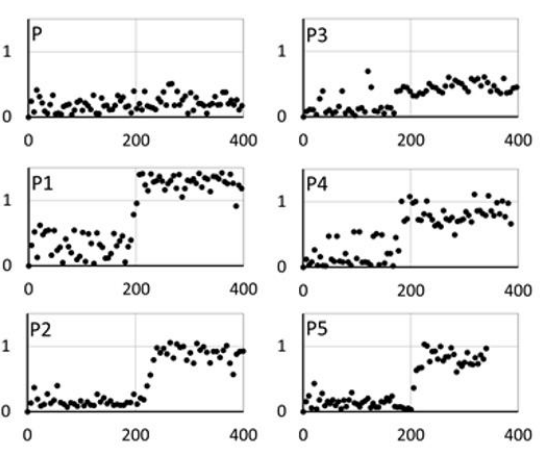

Fig. 10: Microstructure after deformation to rupture. (a) TEM bright field image of an area showing the interface between the eutectic mixture and a dendrite. (b) Orientation map obtained with ASTAR The rphase halo is continuous but the interface with the dendrite is not flat. Along the interface, black arrows are pointing a series of cusps. (c) Correlation map showing traces of dislocations in the $(\mathrm{Mg})$ dendrite and a $\gamma$ phase matrix free of defects except for singularities between the interface and the closest fibres. The blue arrows point the locations of the misorientation profiles displayed below the correlation map. The reference profile $(P)$ drawn in an area free of defects shows negligible misorientation $\left(<0.5^{\circ}\right.$, i.e. resolution limit of the indexation). The profiles $P 1$ to $P 5$ are all characterized by an abrupt change of about $1^{\circ}-1.5^{\circ}$. (d) Virtual Dark Field image revealing features consistent with dislocations in the narrow spacing between the interface and the closest fibres. (e) Virtual Dark Field image showing dislocation traces in the $(\mathrm{Mg})$ dendrite and fibres. The dotted arrow indicates an accumulation of dislocations in the dendrite in the vicinity of a cusp. (Mg-50\% $\gamma$ composite)

\section{Discussion}

The discussion of the mechanical behaviour of the Mg- $\gamma$ composites will examine first what the present study is telling about the $\gamma$ phase deformation, then we will analyse the results in terms of deformation mechanisms. Finally, the key effects identified through the $\mathrm{Mg}-\gamma$ composite study will be discussed with respect to the design of high strength composites.

The experimental section has pointed out the following points concerning the $\gamma$ phase plasticity. First the macroscopic behavior and the microstructural investigation of the deformed $\mathrm{Mg}-\gamma$ composites have evidenced the transmission of deformation through the $\gamma$ phase. This transmission is demonstrated by the existence of a macroscopic strain even though the ductile phase $((\mathrm{Mg})$ dendrites and fibres) is embedded in the $\gamma$ phase matrix. It is confirmed by the microscopic observations of dislocations and twins attesting for the plasticity of the (Mg) dendrites while they are enclosed in the $\gamma$ phase. More precisely the microstructural investigation points out the presence of a halo of $\gamma$ phase separating the $(\mathrm{Mg})$ dendrites from the closest $(\mathrm{Mg})$ fibres of the eutectic mixture. This $\gamma$ phase halo systematically observed in the Mg- $\gamma$ composites is due to specific thermodynamic and kinetic features of solidification [12]. This characteristic feature is then preventing from any connection between the dendrites and makes necessary the transmission of deformation across the Mg- $\gamma$ eutectic mixture. As a 
consequence, the $\gamma$ phase forming the eutectic mixture matrix must show some plasticity. The bulk $\gamma$ phase is known to be hard and brittle at room temperature and to become plastic only above $300^{\circ} \mathrm{C}([18],[19],[20])$, therefore the plasticity attested by the presence of dislocations reveals a size reduction effect resulting from the submicronic scale of the eutectic microstructure. Indeed such size effect on the plasticity of the $\gamma$ phase was already suggested by nanomechanical studies [21]

The fact that the deformation is transmitted between the $\gamma$ phase and the $(\mathrm{Mg})$ fibres raises the more general question of the transmission of deformation between a simple structure (here magnesium) and a structurally complex intermetallic (here the $\gamma$ phase). Our investigations have shown that dislocations propagate through the $\gamma$ matrix and the $(\mathrm{Mg})$ fibres without displaying a significant deviation of the slip traces neither a high TEM contrast at the $\mathrm{Mg} / \gamma$ interface. Slip transfer in multiphase alloys is considered as obeying to the following criterion: minimization of the angle between the intersection of the grain boundary with the glide planes active in each phase, minimization of the Burgers vector of the residual dislocation left at the grain boundary [22]. Therefore dislocations crossing the $\mathrm{Mg} / \gamma$ interfaces without deviation and absence of residual dislocation at the $\mathrm{Mg} / \gamma$ interface suggest a high structural proximity between the $\mathrm{Mg}$ and $\gamma$ phases. This cannot result from a specific orientation relationship between the $(\mathrm{Mg})$ fibre and the $\gamma$ matrix since the orientation maps have shown that the orientation is not well defined and even slightly varies from fibre to fibre.

From a general point of view, Frank and Kasper have demonstrated that the local tetrahedral atom packing induces structural properties that complex metallic alloys have in common. For instance, while the complex metallic alloys do not show dense atomic planes like the hcp or fcc structure, for a small corrugation of about $\pm 0.1 \mathrm{~nm}$, they feature dense corrugated layers equivalent of compact dense planes. This is illustrated in Fig. 11 on the $\gamma$ phase structure by a series of successive atomic layers and the corrugated dense layer that can be built in the direction $<001>$ (other directions are presented in the Appendix B of supplementary material).

(a)

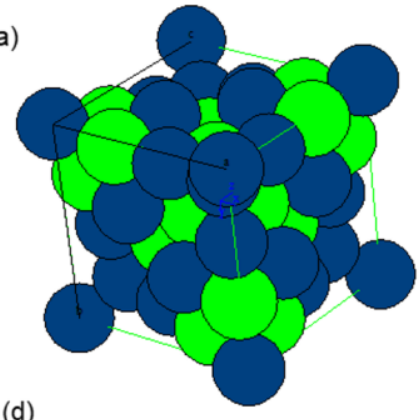

(d)

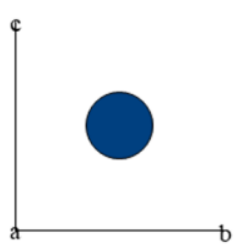

layer 1

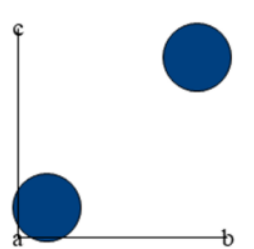

layer 2 (b)

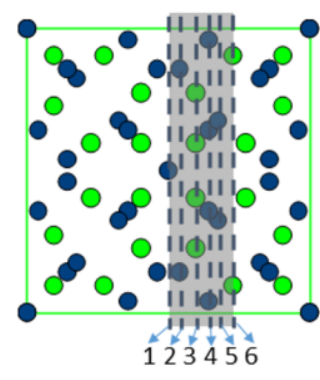

(c)

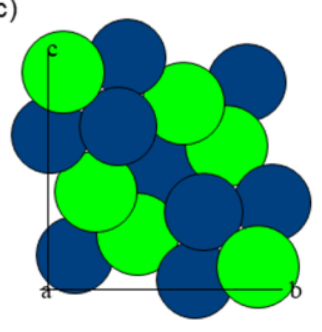

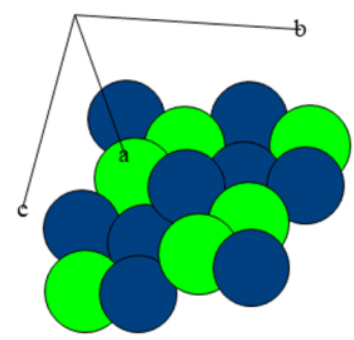

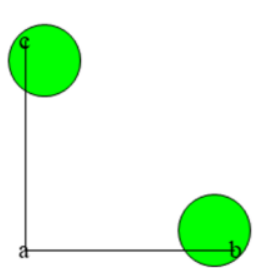

layer 6

(l) 6

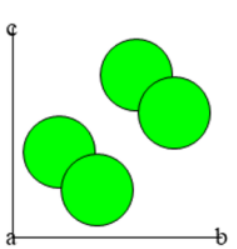

layer 3

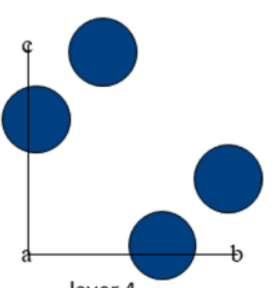

layer 4

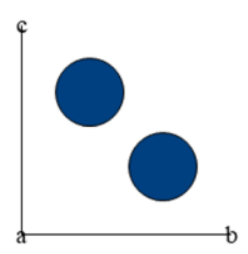

layer 5

Fig. 11: $\mathrm{MMg}_{17} \mathrm{Al} \mathrm{l}_{12}$ phase structure : atomic planar layers and dense corrugated layer. (a) Perspective view of the $\gamma \mathrm{Mg}_{17} \mathrm{Al} \mathrm{I}_{12} \mathrm{phase}$ structure cell (full scale radii). (b) Side view of the $\mathrm{MMg}_{17} \mathrm{Al} \mathrm{l}_{12}$ cell corresponding to a projection along the [001] direction (20\% radii size). The dotted lines labelled 1 to 6 and the grey rectangle respectively indicate successive atomic planar layers and the selection used to build a dense corrugated layer. (c) Projected and perspective view of the corrugated layer corresponding to the grey rectangle selection. Note that for this selection with $0.23 \mathrm{~nm}$ thickness (corrugation $\pm 0.115 \mathrm{~nm}$ ), the layer is dense (full scale radii). (d) Atomic planar layers corresponding to the layers 1 to 6 . Note that they are all characterized by a low atomic density (full scale radii). 
Frank and Kasper have also shown that the coordination polyhedron in complex metallic alloys could be only an icosahedron or three other polyhedra related to the icosahedron. These triangulated polyhedra are associated to the tetrahedral atomic packing. The $\gamma$ phase displays such polyhedral while the Mg hcp structure does not (see supplementary material Appendix $\mathrm{C}$ ). However it can be verified for hcp $\mathrm{Mg}$ and $\gamma \mathrm{Mg}_{17} \mathrm{Al}_{12}$ phase structure that around each atom, similar atomic distances can be found (see supplementary material Appendix C). This local feature together with the existence of dense corrugated layers in various directions can explain the observations of slip traces traversing the $\mathrm{Mg}$ and $\gamma$ phases without deviation.

Though the slip transfer observed between the $\mathrm{Mg}$ and $\gamma$ phase can be related to well-known structural specificities of complex metallic alloys, to our knowledge, such property has never been reported yet. This is certainly due to the brittleness of the complex alloy phases that usually prevents from deformation studies at room temperature. Here it seems that a size effect resulting from the composite microstructure has allowed for deformation of the $\gamma$ phase at room temperature providing information that otherwise could be reached only by advanced nanomechanics techniques.

Regarding now the deformation mechanisms, the stress-strain curves suggest to distinguish three stages (stages A, B, C in Fig. 12). The first part of the curve (stage A) corresponds to an elastic deformation, with bulk moduli ranging from $45 \mathrm{GPa}$ for composites with a low volume fraction of $\gamma$ phase to $60 \mathrm{GPa}$ for the highest $\gamma$ volume fractions. These values are respectively close to the elastic moduli of magnesium (about $45 \mathrm{GPa}$ depending on the alloy composition) and to the one of the $\gamma$ phase (65 GPa) [21]. The stage B corresponds to a low stress plastic deformation almost forming a plateau for a yield stress of about $100 \mathrm{MPa}$ and showing a quite similar amount of plastic deformation ( $\Delta \varepsilon \sim 0.01$ ) for all composites. The fact that magnesium alloys are known for yielding at about $100 \mathrm{MPa}$ is not sufficient to account for this low stress deformation because the $(\mathrm{Mg})$ fibres and dendrites are embedded in the $\gamma$ phase matrix that is not expected to yield at low stress. However on deformed sample we have noticed deformation contrast bands traversing a dendrite and continuing along the eutectic cell boundary. This observation suggests that deformation can be transmitted between dendrites along paths following the eutectic cell boundaries. The eutectic cell boundaries being native discontinuities formed during the eutectic solidification, they do not require to be nucleated. Moreover, if the eutectic cell boundaries were yielding at a stress similar to the magnesium one, it could explain why all the composites exhibit approximately the same deformation amount for stage B. For all these reasons, we propose to consider the paths following the eutectic cell boundaries as a first way to transmit the deformation between dendrites.

Concerning the transmission of deformation within the eutectic matrix, our investigations have pointed out that, in samples deformed to rupture, dislocations are preferentially located in the spacing between adjacent fibres or between a fibre and the interface with a dendrite. In these submicrometric spacing, the dislocations are forming pile-ups. Also the formation of small $\gamma$ phase domains separated by misorientations of several degrees suggests the localization of a high density of dislocations forming slip bands. Consequently, the dislocation pile-ups and the slip bands can constitute a deformation path across the eutectic mixture. However, compared to the first path following the eutectic cell boundaries, this second path involves defects that need to be nucleated in the homogeneous $\gamma$ phase matrix that should be then characterized by a higher yield stress consistent with the deformation stage $\mathrm{C}$.

For summarizing, based on the two paths deduced from the microstructural observations, we propose to interpret the Mg- $\gamma$ composites behaviour as summarized in Fig. 12. After the elastic deformation (stage A), the low stress behaviour (stage $B$ ) is accountable to the deformation of dendrites and propagation of the deformation across the eutectic mixture along the eutectic cell boundaries. Regarding the higher stress behaviour (stage C), the deformation is transmitted across the $\gamma$ phase along a path formed by slip bands and dislocation pile-ups. The plasticity of the $\gamma$ phase of the eutectic mixture is due to a reduced yield stress resulting from the submicronic scale of the eutectic mixture. 


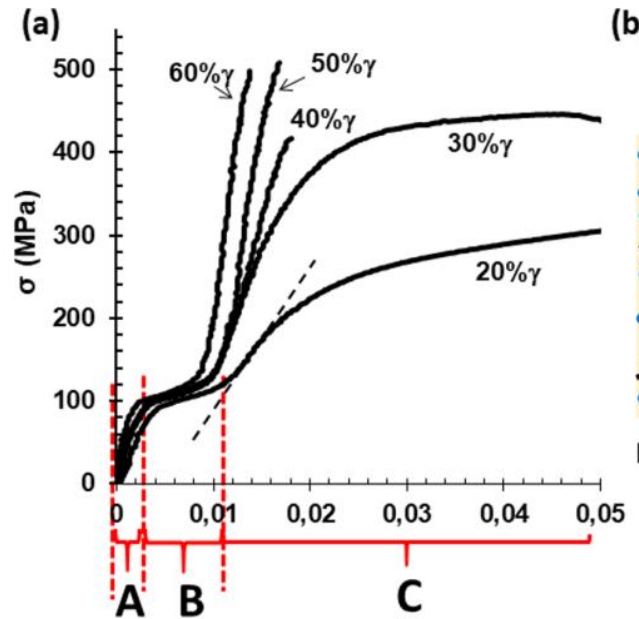

(b)

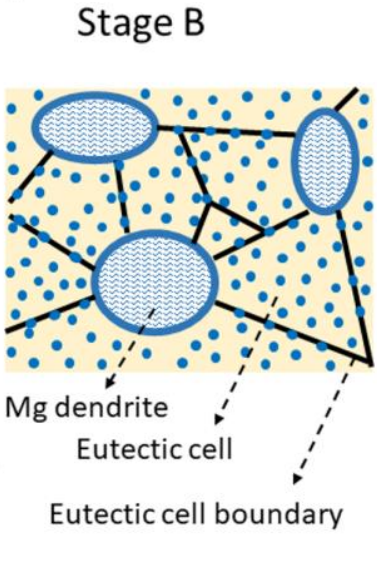

(c) Stage C

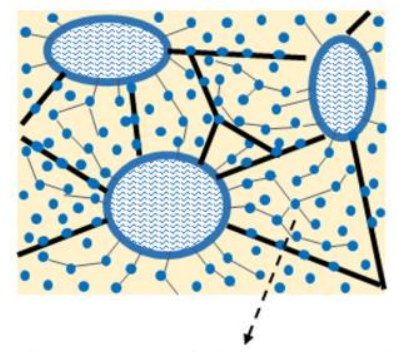

formation of dislocation pile ups and slip bands within the eutectic cells

Fig. 12: Deformation behaviour and proposed mechanisms. (a) Stress-strain curves of the Mg- $\gamma$ composites revealing three deformation stages labelled A, B, C. Stage A corresponds to the elastic deformation, stages $B$ and $C$ to plastic deformation. The dotted line points out a change in the stage $C$ plastic behaviour of the Mg-20\% $\gamma$ composites suggesting an estimate for the yield point of the y phase in the eutectic mixture. (b) Stage B : Deformation occurs in the (Mg) dendrites and is transmitted by the eutectic cell boundaries. (c) Stage $C$ : deformation occurs in the eutectic cells with the formation of dislocation pile-ups and slip bands.

In the stage $\mathrm{C}$, opposite to the stage $\mathrm{B}$, the deformation behaviour depends on the $\gamma$ phase volume fraction. For $\gamma$ phase volume fraction smaller than $40 \%$, the composites are plastic while for fractions equal to or higher than $40 \%$, they break at high stress ( $400 \mathrm{MPa}$ ) without plasticity except the low stress one. According to the TEM observations, dislocations are observed in all the deformed composites in stage $\mathrm{C}$. As a consequence, the $\gamma$ phase being the matrix of the eutectic mixture of all the $\mathrm{Mg}-\gamma$ composites, its yield stress must be lower than the maximum stress exhibited by the weakest Mg- $\gamma$ composite. Indeed the behavior of the Mg-20\% composite suggests a value of about $180 \mathrm{MPa}$ that is corresponding to a change in the plastic behavior in the stage $\mathrm{C}$ (inflexion point marked by the dotted line on stress curve, Fig. 12(a)). The fact that this value is rather close to the yield value of the $\mathrm{Mg}$ dendrites is consistent with the short stage $\mathrm{B}$ observed for all composites. Also this rather low value is consistent with a similarity of mechanical behavior of $\mathrm{Mg}$ and $\gamma \mathrm{Mg}_{17} \mathrm{Al}_{12}$ at small scale suggested by nanomechanical investigation [21].

Regarding now the influence of the $\gamma$ phase volume fraction in the stage $C$, it can be analysed with respect to the strain accumulation in the $\gamma$ phase matrix resulting from the slip bands and dislocations pile-ups. Such strain accumulation at the interface with dendrites will be all the more easy to relieve that the dendrite volume fraction is high. Therefore when the dendrite fraction is low (i.e. the $\gamma$ phase volume fraction is high) the damage accumulation in the eutectic mixture may become too high and then leads to rupture. This interpretation is consistent with the change in a brittle /ductile behaviour occurring at $40 \% \gamma$ phase volume fraction ( $50 \%$ dendrite volume fraction).

Furthermore it was noticed that cracks in the eutectic mixture were stopped at the $(\mathrm{Mg})$ dendrites. This behaviour reminds of fatigue crack propagation in two phase materials where cracks propagating in the hard phase are attracted by the softer one [23]. This effect requires some contrast between the elastic properties of the two phases [24] which is indeed happening in the $\mathrm{Mg}-\gamma$ composites. The fact that dislocations pile-ups and slip bands are observed along directions normal to the $\mathrm{Mg} / \gamma$ interface is also in agreement with the attraction effect of soft inclusion. Moreover like rubber particles in polymer acting as "craze terminators" [25], soft inclusion can 
contribute to delay the fracture. This can explain why the Mg- $\gamma$ composites with high volume fraction break at quite high stress (400-450 MPa) and suggests that the soft inclusion effect is a key effect for the deformation of Mg- $\gamma$ composites.

The deformation mechanism described above for $\mathrm{Mg}-\gamma$ composites is quite similar to the one earlier proposed by Zhang et al. for BMG-dendrites composites [26]. However there are some differences. First of all, the high elastic deformation of the BMG matrix allows the BMG-dendrites composites to accommodate the dendrites plastic deformation over a larger extent (frequently up to $2 \%$ ). On the other hand for $\mathrm{Mg}-\gamma$ composites, the eutectic matrix is able to yield at low stress because it is heterogeneous and contains native discontinuities while the BMG dendrites composites have an homogeneous featureless amorphous matrix [14]. Regarding the deformation stage of $\mathrm{Mg}-\gamma$ composites (stage $\mathrm{C}$ ), the plasticity of the $\gamma$ phase matrix can be explained by the submicronic scale of the eutectic microstructure. The localisation of dislocations and the formation of slip bands can be accounted for by the difficult propagation of dislocations in the complex atomic structure of the $\gamma$ phase. In other words, our interpretation of the stage $\mathrm{C}$ behaviour relies on the specificities of the CMA structure and on the small scale of the eutectic microstructure. In addition, the propagation of deformation is characterized by features consistent with a soft inclusion attraction.

In metallic glass ribbons as well as in BMG systems or their composites, similar observations have not been reported. However nanoscale heterogeneities are frequently invoked in the understanding of glass plasticity [27],[28]. For instance, atomic simulations have pointed out a medium range order called soft spots that could explain the glass mechanical behaviour [29], [30]. Unfortunately because of the amorphous structure direct evidences for these soft spots are difficult to obtain [31]. To that respect, eutectic mixture involving a CMA phase could provide attractive model systems since, as pointed out by the corrugated layer described above, the tetrahedral local order of CMA phases makes them quite isotropic and from that point of view close to an amorphous alloy.

The study of the Mg- $\gamma$ composites has revealed the combination of three key effects: the structural specificities of CMA phase allowing the transmission of deformation between simple and complex structure, the size effect on the plasticity of the $\gamma$ phase and the soft inclusion effect. This result could be of interest in the design of new high strength intermetallic composites. In the last decades, various systems have been pointed out for their remarkable mechanical properties. Besides the case of BMG dendrites composites, high strength combined to high ductility has been reported for Zr-based composites (the so called MINCs composites) [32], for light alloys eutectic composites [33], [34] and for nanoeutectic alloys [35]. Though most of these systems (if not all) are containing CMA phases, the structural point of view is rarely considered and properties are rather analysed in terms of microstructure scale. However, among the systems listed above, the nanoeutectic composites are very fine scale while the MINCs alloys display coarser features and the light alloys eutectic composites are characterized by a bimodal microstructure. Hence the scale alone does not account for the outstanding properties of these composites. All these systems have also in common to be made of a soft phase and a very hard and often brittle phase which is the matrix. In other words, like in the Mg-Al system, the soft phase is embedded in the hard one. According to the present study of $\mathrm{Mg}-\gamma$ composites, such microstructure allows for a soft inclusion effect able to delay the fracture propagation and consequently to reach higher deformation. Though dendrites have been identified as having an important role in the propagation of shear band and cracks [33],[36], the fact that the soft phase was embedded in the hard one and the resulting soft inclusion effect were not specifically emphasized. Indeed the soft inclusion effect makes possible to overcome the usual brittleness of CMA phases and could constitute a useful guideline in the design of composites with a high level of mechanical properties. Finally, one of the main findings of the present work is that instead of trying to reinforce a soft matrix, softening a hard one appears as a route of interest for designing new materials with enhanced properties. 


\section{Conclusion}

The present work was centered on the room temperature deformation of $\mathrm{Mg}-\gamma \mathrm{Mg}_{17} \mathrm{Al}_{12}$ composites containing various amounts (between 20 and 60 vol.\%) of the complex $\gamma$ phase. Combining compression tests with finescale microstructural investigations led to the following key features:

- The as-cast microstructure of the composites consists of $(\mathrm{Mg})$ dendrites surrounded by cells of the fibrous (Mg)- $\gamma$ eutectic mixture. It can also be described as a matrix of hard $\gamma$ phase containing dendrites and fibres of the soft metallic $(\mathrm{Mg})$ phase. The same microstructural features are observed after deformation.

All the composites exhibit plastic deformation under compression at room temperature. It is characterized by two stages. The first one occurs for all composites at low stress ( $100 \mathrm{MPa})$, low strain $(<0.01)$. The second stage is characterized by a deformation behaviour depending on the $\gamma$ phase volume fraction, namely the composites containing 20 and 30 vol.\% of the $\gamma$ phase display a significant plastic deformation with strain hardening while the composites with $\gamma$ phase volume fractions equal to or larger than $40 \%$ show only negligible additional deformation before breaking at high stress (> $400 \mathrm{MPa}$ ).

- The macroscopic behaviour and the microstructural investigation are consistent with the activation of several deformation mechanisms: twinning and dislocation multiplication in the $(\mathrm{Mg})$ dendrites followed by their propagation across the eutectic mixture throughout the $\gamma$ matrix and the $(\mathrm{Mg})$ fibres along the eutectic cell boundaries or along dislocation pileups and slip bands resulting from the localization of the $\gamma$ phase dislocations.

- The transmission of the deformation between the simple Mg structure and the complex $\gamma$ phase one that has been here experimentally evidenced can be explained by the specificities of the complex $\gamma$ phase structure ; namely the proximity of the atomic distances and the existence of corrugated layers in many directions acting as dense glide planes. These specificities can also explain why slip transfer between the $\mathrm{Mg}$ and $\gamma$ phases is possible while the orientation relationship is not well defined.

- The observations are also revealing features of the $\mathrm{Mg}-\gamma$ eutectic mixture which are of major interest for the mechanical behaviour: - the plasticity of the hard and brittle $\gamma$ phase eutectic matrix that is attesting for a size effect resulting from the fine scale of the microstructure, - a localization of deformation in agreement with a soft inclusion effect.

More generally the combination of soft inclusion effect, size reduction and specific atomic features of complex metallic alloy phase provides a frame of understanding for the plasticity of various recently developed composites like the BMG-dendrites and other composites that all have the specificity to involve complex metallic phases and a soft phase embedded in the hard and brittle one. The transmission of deformation between the simple and complex metallic phases is a point that is rarely addressed though it can be of primary interest for developing new metallic alloy composites. Also the soft inclusion effect appears as a key effect that allows to overcome the brittleness of CMA phases and then can give rise to high strength composite systems with a high ductility.

From the characterization point of view, the present microstructural study illustrates how the ASTAR advanced nanodiffraction method constitutes a valuable tool to quantitatively study complex microstructures and significantly complement the classical TEM imaging. This method has been here particularly efficient to investigate dislocation configurations like pile-ups and slip bands in the composites. It appears as a most appropriate technique to investigate and decipher the microstructure of complex/simple alloys composite systems. 
Acknowledgments: This research has benefited from the characterization equipments of the Grenoble INP - CMTC platform supported by the Centre of Excellence of Multifunctional Architectured Materials "CEMAM" ${ }^{\circ} A N R-10$ LABX-44-01 funded by the Investments for the Future programme

\section{References:}

[1] J.-M. Dubois, E. Belin-Ferré, eds., Complex metallic alloys: fundamentals and applications, Wiley-VCH, Weinheim, 2011.

[2] F.C. Frank, J.S. Kasper, Complex alloy structures regarded as sphere packings. I. Definitions and basic principles, Acta Crystallogr. 11 (1958) 184-190.

[3] A.K. Sinha, Topologically close-packed structures of transition metal alloys, Prog. Mater. Sci. 15 (1972) 81-185.

[4] S. Scudino, K.B. Surreddi, S. Sager, M. Sakaliyska, J.S. Kim, W. Löser, J. Eckert, Production and mechanical properties of metallic glass-reinforced Al-based metal matrix composites, J. Mater. Sci. 43 (2008) 4518-4526. https://doi.org/10.1007/s10853-008-2647-5.

[5] S. Scudino, G. Liu, M. Sakaliyska, K.B. Surreddi, J. Eckert, Powder metallurgy of Al-based metal matrix composites reinforced with $\beta$-Al3Mg2 intermetallic particles: Analysis and modeling of mechanical properties, Acta Mater. 57 (2009) 4529-4538. https://doi.org/10.1016/j.actamat.2009.06.017.

[6] A. Singh, H. Somekawa, T. Mukai, Compressive strength and yield asymmetry in extruded Mg-Zn-Ho alloys containing quasicrystal phase, Scr. Mater. 56 (2007) 935-938.

https://doi.org/10.1016/j.scriptamat.2007.02.015.

[7] T. El Kabir, A. Joulain, V. Gauthier, S. Dubois, J. Bonneville, D. Bertheau, Hot isostatic pressing synthesis and mechanical properties of Al/Al-Cu-Fe composite materials, J. Mater. Res. 23 (2008) 904-910. https://doi.org/10.1557/jmr.2008.0111.

[8] S.L. Pramod, S.R. Bakshi, B.S. Murty, Aluminum-Based Cast In Situ Composites: A Review, J. Mater. Eng. Perform. 24 (2015) 2185-2207. https://doi.org/10.1007/s11665-015-1424-2.

[9] R.M. Aikin, Jr. The Mechanical Properties of In-Situ Composites, JOM,49 (8) (1997), pp. 35-39., (n.d.).

[10] «Pandat- Phase Diagram Calculation Engine for Multicomponent Systems», CompuTherm LLC, $437 \mathrm{~s}$. Yellowstone DR.,Suite 217.

[11] P.Villars, K. Cenzual, Pearson's Crystal Data - Crystal Structure Database for Inorganic Compounds, Release 2015/16, ASM.

[12] P. Donnadieu, S. Benrhaiem, C. Tassin, F. Volpi, J.-J. Blandin, Preparation, microstructure and properties of magnesium-үMg17Al12 complex metallic alloy in situ composites, J. Alloys Compd. 702 (2017) 626-635. https://doi.org/10.1016/j.jallcom.2017.01.294.

[13] C.C. Hays, C.P. Kim, W.L. Johnson, Microstructure controlled shear band pattern formation and enhanced plasticity of bulk metallic glasses containing in situ formed ductile phase dendrite dispersions, Phys. Rev. Lett. 84 (2000) 2901.

[14] J. Qiao, In-situ Dendrite/Metallic Glass Matrix Composites: A Review, J. Mater. Sci. Technol. 29 (2013) 685-701. https://doi.org/10.1016/j.jmst.2013.05.020. 
[15] ASTAR ${ }^{\text {TM }}$ by NanoMEGAS company, http://www.nanomegas.com/

[16] E.F. Rauch, M. Véron, Automated crystal orientation and phase mapping in TEM, Mater. Charact. 98 (2014) 1-9. https://doi.org/10.1016/j.matchar.2014.08.010.

[17] S. Guldberg, N. Ryum, Microstructure and crystallographic orientation relationship in directionally solidified Mg-Mg 17 Al 12-eutectic, Mater. Sci. Eng. A. 289 (2000) 143-150.

[18] J. Ragani, P. Donnadieu, C. Tassin, J.J. Blandin, High-temperature deformation of the Y-Mg17Al12 complex metallic alloy, Scr. Mater. 65 (2011) 253-256. https://doi.org/10.1016/j.scriptamat.2011.04.022.

[19] H.N. Mathur, V. Maier-Kiener, S. Korte-Kerzel, Deformation in the $\gamma$-Mg 17 Al 12 phase at 25-278 ${ }^{\circ} \mathrm{C}$, Acta Mater. 113 (2016) 221-229. https://doi.org/10.1016/j.actamat.2016.05.001.

[20] K. Hagihara, K. Hayakawa, Plastic deformation behavior and operative slip systems in Mg17Al12 single crystals, Mater. Sci. Eng. A. 737 (2018) 393-400. https://doi.org/10.1016/j.msea.2018.09.056.

[21] M.-X. Zhang, H. Huang, K. Spencer, Y.-N. Shi, Nanomechanics of Mg-Al intermetallic compounds, Surf. Coat. Technol. 204 (2010) 2118-2122. https://doi.org/10.1016/j.surfcoat.2009.11.031.

[22] A. Misra, R. Gibala, Slip transfer and dislocation nucleation processes in multiphase ordered Ni-Fe-Al alloys, Metall. Mater. Trans. A. 30 (1999) 991-1001. https://doi.org/10.1007/s11661-999-0152-3.

[23] P.O.Bouchard. Damage and Discrete Crack Propagation Modelling : Some Results and Challenges For 2d And 3d Congurations. , Proc. $11^{\text {th }}$ International Conference on Fracture, ICF11 Turin (2005) 982-987

[24] H. Ming-Yuan, J.W. Hutchinson, Crack deflection at an interface between dissimilar elastic materials, Int. J. Solids Struct. 25 (1989) 1053-1067.

[25] W.G. Perkins, Polymer toughness and impact resistance, Polym. Eng. Sci. 39 (1999) 2445-2460. https://doi.org/10.1002/pen.11632.

[26] T. Zhang, H.Y. Ye, J.Y. Shi, H.J. Yang, J.W. Qiao, Dendrite size dependence of tensile plasticity of in situ Tibased metallic glass matrix composites, J. Alloys Compd. 583 (2014) 593-597.

https://doi.org/10.1016/j.jallcom.2013.08.201.

[27] N. Wang, J. Ding, F. Yan, M. Asta, R.O. Ritchie, L. Li, Spatial correlation of elastic heterogeneity tunes the deformation behavior of metallic glasses, Npj Comput. Mater. 4 (2018) 19. https://doi.org/10.1038/s41524-0180077-8.

[28] Y.M. Lu, J.F. Zeng, S. Wang, B.A. Sun, Q. Wang, J. Lu, S. Gravier, J.J. Blandin, W.H. Wang, M.X. Pan, C.T. Liu, Y. Yang, Structural Signature of Plasticity Unveiled by Nano-Scale Viscoelastic Contact in a Metallic Glass, Sci. Rep. 6 (2016) 29357. https://doi.org/10.1038/srep29357.

[29] J. Ding, S. Patinet, M.L. Falk, Y. Cheng, E. Ma, Soft spots and their structural signature in a metallic glass, Proc. Natl. Acad. Sci. 111 (2014) 14052-14056. https://doi.org/10.1073/pnas.1412095111.

[30] B. Wang, L. Luo, E. Guo, Y. Su, M. Wang, R.O. Ritchie, F. Dong, L. Wang, J. Guo, H. Fu, Nanometer-scale gradient atomic packing structure surrounding soft spots in metallic glasses, Npj Comput. Mater. 4 (2018) 41. https://doi.org/10.1038/s41524-018-0097-4. 
[31] L. Tian, C.A. Volkert, Measuring Structural Heterogeneities in Metallic Glasses Using Transmission Electron Microscopy, Metals. 8 (2018) 1085. https://doi.org/10.3390/met8121085.

[32] K.J. Dusoe, S. Vijayan, T.R. Bissell, J. Chen, J.E. Morley, L. Valencia, A.M. Dongare, M. Aindow, S.-W. Lee, Strong, ductile, and thermally stable Cu-based metal-intermetallic nanostructured composites, Sci. Rep. 7 (2017) 40409. https://doi.org/10.1038/srep40409.

[33] J.M. Park, N. Mattern, U. Kühn, J. Eckert, K.B. Kim, W.T. Kim, K. Chattopadhyay, D.H. Kim, High-strength bulk Al-based bimodal ultrafine eutectic composite with enhanced plasticity, J. Mater. Res. 24 (2009) 26052609. https://doi.org/10.1557/jmr.2009.0297.

[34] G.A. Song, D.H. Kim, D.H. Kim, M.H. Lee, J.K. Lee, J.M. Park, J. Eckert, Y. Seo, K.B. Kim, Deformation mechanisms of a bimodal eutectic Mg72Cu5Zn23 ultrafine composite, Mater. Lett. 64 (2010) 534-536. https://doi.org/10.1016/j.matlet.2009.11.068.

[35] R. Li, G. Liu, M. Stoica, J. Eckert, FeCo-based multiphase composites with high strength and large plastic deformation, Intermetallics. 18 (2010) 134-139. https://doi.org/10.1016/j.intermet.2009.07.003.

[36] J.M. Park, T.E. Kim, S.J. Kim, W.T. Kim, U. Kühn, J. Eckert, D.H. Kim, Improving the Mechanical Properties of Fe-Nb-(Ni-Mn) Dendrite-Ultrafine Eutectic Composites via Controlling the Primary Phase Features, Metall. Mater. Trans. A. 43 (2012) 2680-2686. https://doi.org/10.1007/s11661-012-1105-9. 